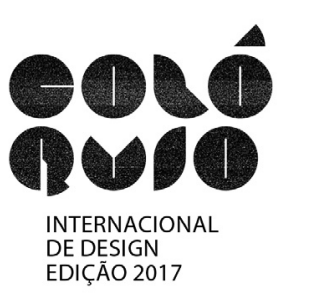

\title{
Uma abordagem sobre design de informação na campanha de divulgação da vacinação contra gripe 2017 entre o público-alvo professores da rede pública e particular em Minas Gerais
}

\author{
Marcos da Silva Araújo; \\ Akemi Alessi Ishihara; \\ Julio Alessi;
}

resumo:

O objetivo desse estudo é analisar os motivos de uma baixa adesão por parte dos professores, a campanha de vacinação contra o a influenza 2017, que se iniciou no dia 17 de abril com o título: "Campanha Nacional de Vacinação Contra a Gripe 2017", através de uma análise dos conteúdos informacionais de peças gráficas impressas (cartazes, folhetos e flyers) criadas e utilizadas por órgãos públicos e empresas jornalísticas na divulgação. Esse estudo teve como base uma pesquisa exploratória composta de duas fases. Na primeira fase foram selecionados e analisados os cartazes de divulgação criados pelo SUS, Secretaria Estadual de Saúde de Minas Gerais e Secretarias Municipais de Saúde de quatro municípios mineiros: Secretarias Municipais de Saúde de Belo Horizonte, Rio Pomba, Campanha e Lagoa da Prata; infográficos publicados no jornal Folha de São Paulo de circulação nacional e no jornal Hoje em Dia de circulação regional, a partir dos pressupostos teóricos do design da informação. Na segunda fase, as mesmas peças foram analisadas quanto ao conteúdo e eficiência informacional por professores de uma instituição de ensino superior em um grupo de foco. A partir dessas duas análises foi possível levantar falhas técnicas no conteúdo e verificar que há a necessidade de se realizar uma pesquisa etnográfica para aumento da eficiência comunicacional com esse público-alvo nas próximas campanhas de vacinação contra gripe. Com base nos resultados obtidos, reforça a necessidade da participação de um profissional de design da informação no processo de concepção e adequação das peças gráficas em campanhas do gênero.

palavras-chave:

Design da Informação; Informação em campanha de vacinação; Sensibilização de professores. 


\section{A dinâmica das campanhas de vacinação no Brasil}

O planejamento anual de vacinações, realizado através do PNI - Programa Nacional de Imunizações, criado em 1973, tem por objetivo erradicar e controlar doenças no Brasil. Anualmente são ofertadas mais de 300 milhões de doses de vacinas, soros e imunoglobulinas gratuitamente pelo SUS - Sistema Único de Saúde, conforme o calendário de vacinação brasileiro. Este calendário é elaborado a partir dos interesses prioritários de saúde pública que contemplam a situação epidemiológica, o risco, a vulnerabilidade e as especificidades sociais das diferentes regiões do Brasil. O Ministério da Saúde tem alterado periodicamente o calendário de vacinação para atingir um número maior de pessoas a serem imunizadas. Atualmente ele contempla a distribuição de 42 tipos de imunobiológicos e 25 vacinas para crianças, adolescentes, adultos, gestantes, idosos e povos indígenas em todos os estados do país. Entre elas está a vacina contra a gripe (PORTAL SAÚDE, 2017 e MINISTÉRIO DA SAÚDE, 2017).

Todas as doenças consideradas nesse calendário podem voltar a se tornar recursivas e ocasionar surtos ou epidemias, daí a preocupação do Ministério da Saúde em realizar campanhas de divulgação e sensibilização para levarem o público-alvo a comparecer aos postos de saúde municipais durante os períodos de campanha e tomar todas as vacinas previstas.

As campanhas de vacinação contra gripe iniciaram em 1999 e até 2010 abrangiam apenas idosos e alguns grupos de risco. A partir de 2011 novos grupos populacionais passaram a ser contemplados. Como em outras campanhas, acontecem a partir da soma de esforços da União, das Secretarias Estaduais de Saúde e Secretarias Municipais de Saúde. As campanhas envolvem um grande esforço de mobilização. Em 2016, foram aproximadamente 240 mil profissionais e 65 mil postos de vacinação em todo Brasil (MARREIROS et al, 2016).

No dia 17 de abril teve início a Campanha Nacional de Vacinação Contra a Gripe 2017. O Ministério da Saúde adquiriu 60 milhões de doses para a imunização com o objetivo de diminuir o número de internações e óbitos decorrentes de suas complicações. A meta inicial era vacinar 54,2 milhões de pessoas que integram os grupos prioritários até o dia 26 de maio, número que corresponde a $90 \%$ do público-alvo (PORTAL BRASIL, 2017). Além de idosos, gestantes, mulheres puérperas, crianças, indígenas e trabalhadores da área de saúde, passaram a fazer parte do público-alvo, os professores das redes pública e particular. Esse último grupo corresponde a 2,3 milhões de profissionais em todo o País (PORTAL SAÚDE, 2017), sendo $253 \mathrm{mil}$ em Minas Gerais (SAÚDE MG, 2017). A campanha de vacinação 2017 foi prorrogada até o dia 9 de junho, de acordo com o Ministério da Saúde, devido à adesão abaixo do esperado. Até o dia 25 de maio, véspera do encerramento previamente previsto, 34,5 milhões, $63,6 \%$ haviam recebido a sua dose (FOLHA DE SÃO PAULO, 2017). Conforme o G1 (2017), os dados contabilizados até o dia 25 de maio mostravam que os idosos haviam alcançado os maiores índices de cobertura: $72,4 \%$, as mulheres puérperas $71,2 \%$, os indígenas $68,6 \%$, os trabalhadores de saúde $64,2 \%$, os professores da rede pública e privada $60,2 \%$, as gestantes $53,4 \%$ e as crianças $49,9 \%$. No fechamento da campanha no dia 09 de junho, a meta de $90 \%$ dos públicos-alvo não havia sido atingida nacionalmente. Foram vacinadas 43.973.009, $82,53 \%$ da cobertura esperada (PORTAL DA SAÚDE, 2017).

De acordo com o SUS (2017), a divulgação da campanha foi realizada com o uso de material impresso (cartaz e folder), mobiliário urbano e mídia televisiva e radiofônica. O foco das mensagens foi a importância da vacinação, as características específicas de cada grupo prioritário e o objetivo do governo federal com a imunização. As ações aconteceram em nível federal, estadual e municipal.

Tendo em vista o esforço de comunicação empregado pelos diversos atores envolvidos na campanha, o que provocou a adesão abaixo do esperado?

Este trabalho tem como objetivo analisar o conteúdo informacional da campanha de divulgação da vacinação contra a gripe 2017. Propõe também analisar qual a contribuição que o design de informação traria para as próximas campanhas para aumentar a eficiência no processo de vacinação entre os professores da rede pública e particular, tendo em vista que um de seus objetivos é exatamente otimizar a seleção, organização e apresentação da informação para uma determinada audiência, com o propósito de se obter maior entendimento, absorção e retenção dos conteúdos. "Deve-se, com isso, buscar uma familiaridade entre o diálogo das mensagens verbo-visuais e os grupos de populações específicas, almejando mais efetividade das metas propostas pelo Ministério da Saúde" (FREITAS ET AL, 2014, p. 295). 


\section{A divulgação da campanha entre os públicos de interesse}

Uma vacina trata-se do mecanismo de controle para algumas doenças infectocontagiosas. O princípio de funcionamento é a inoculação de um antígeno na corrente sanguínea de uma pessoa para que haja a produção de anticorpos (FUNDAÇÃO NACIONAL DE SAÚDE, 1998). De acordo com a Declaração de Alma-Ata , Conferência Internacional sobre cuidados primários de saúde realizada em setembro de 1978, um dos pontos básicos relativos à saúde pública está no processo de imunização contra as principais enfermidades infecciosas, como a gripe.

A gripe, uma doença contagiosa contraída pelo contato com secreções das vias respiratórias eliminadas por pessoas contaminadas ao falar, tossir, espirrar e através das mãos e objetos contaminados, quando entram em contato com mucosas. O vírus da gripe do tipo A é o mais temido pelo seu poder de causar um grande impacto na saúde pública, tendo provocado grandes pandemias, atingindo populações em escala continental e global (NEWS MEDICAL, 2017). Conforme a OMS, estima-se que a influenza ataca 5 a $10 \%$ dos adultos e 20 a $30 \%$ das crianças, causando 3 a 5 milhões de casos graves e 250.000 a 500.000 mortes por ano. Em 2016 foram registrados 12.174 casos confirmados de síndrome respiratória aguda grave causados pelo vírus A no Brasil. A síndrome é uma complicação da gripe que causou 2.220 óbitos, número superior aos registrados nos anos anteriores. Do total de mortes 1.982 foram causadas por influenza A(H1N1) $(\mathrm{G} 1,2017)$.

O público-alvo da vacinação é constituído pelos grupos com maior risco de contrair a gripe e de desenvolver complicações a partir dela (MINISTÉRIO DA SAÚDE, 2017). Em 2017, os professores das redes pública e particular foram incluídos pelo SUS no grupo de risco da vacinação contra a influenza. O objetivo da inclusão é de prevenir que os profissionais de educação, que mantêm contato com um grande número de estudantes, sejam imunizados para não serem transmissores nem receptores do vírus (O GLOBO, 2017).

Apesar dos esforços de comunicação, diferentemente do ano de 2016, quando ocorreu um surto da doença com expressivo número de casos notificados, a vacinação em 2017 iniciou com baixa procura por parte do público-alvo (O GLOBO, 2017). O grupo formado pelos professores das redes pública e particular, registrou até o encerramento previsto da vacinação apenas a quinta maior adesão dos sete grupos prioritários (PORTAL DA SAÚDE, 2017), algo que gera estranhamento, tendo em vista que são profissionais com maior nível informacional (COUTINHO E LISBOA, 2011) e que em princípio seriam mais susceptíveis ao conteúdo divulgado na campanha. Profissionais como os professores, com expertise em determinadas áreas são capazes de pensar efetivamente sobre problemas de uma forma diferente. Pesquisas mostram que esse tipo de profissional tem conhecimentos que afetam o que ele percebe e como ele organiza, representa e interpreta informação em um contexto (BRANSFORD; BROWN; COCKING, 2000). O processo de aprendizagem de um professor é profundamente afetado pelo contexto e por suas práticas. Ele precisa de múltiplas oportunidades para aprender novas informações e entender suas implicações em situações reais (TIMPERLEY ET AL, 2008).

A produção da informação é operacionalizada através de práticas bem definidas e se apóia em um processo de transformação orientado por uma racionalidade técnica que lhe é específica; representa atividades relacionadas à reunião, seleção, codificação, redução, classificação e armazenamento de informação. Todas essas atividades estão orientadas para a organização e controle de estoques de informação, para uso imediato ou futuro (BARRETO, 2001).

Para Buckland (1991), a informação pode ser considerada em diferentes perspectivas: como processo - "information-as-process"; conhecimento - "information-as-knowledge"; ou "informativos" "information-as-thing", abordando o concreto, o abstrato e o processo da informação. Ela assume a dimensão de processo quando sua ação é informar; de conhecimento, quando se relaciona a um fato, sujeito ou evento particular; e como coisa, assim considerando o conceito de informação para objetos, tais como dados e documentos, que são referidos como informação porque são considerados como "informativos", como portadores da qualidade de carregar o conhecimento ou comunicar informação. Por exemplo, uma "rocha" seria apenas um objeto desprovido de informação até que um arqueólogo a encontre e a identifique como um fóssil. Nesse momento se torna informação e propiciará ao 
arqueólogo um conjunto de dados que pelo processo serão convertidos em conhecimento. Já o fóssil apenas se tornará um documento da informação a partir do momento que seja fonte de instrução.

Tradicionalmente $40 \%$ da atividade na área da saúde consiste na captura e processamento da informação que em si não é capaz de impelir transformações comportamentais. É necessário que hajam ações sistêmicas que considerem a diversidade cultural brasileira e os aspectos subjetivos dos indivíduos, assim, a construção da mensagem deverá sopesar os repertórios midiáticos característicos de cada grupo. Freitas et al relacionam os repertórios midiáticos ao processo comunicacional:

Entende-se então que o processo de desenvolvimento e circulação de repertórios midiáticos é relevante na atualidade, principalmente pela abrangência ao público e sua influência sobre o cotidiano social e de saúde. Assim, o processo comunicacional confere visibilidade aos acontecimentos e informações, reduzindo barreiras espaciais e temporais, possibilitando novas comunicações além da interação física. Essas formas de comunicação promovem impacto no meio social e alteram a organização da vida cotidiana (FREITAS ET AL, 2014, p.296).

O sistema de informação que envolve os processos relativos a assistência à saúde, abordando especificamente o SUS, é complexo e fluido, e, neste caso, existe a necessidade de afilar a sua eficácia, o que norteará políticas públicas relativas à gestão do setor. Santos (2014), pondera que:

Tem-se observado, entretanto, que apesar do avanço no âmbito do sistema de informação em saúde com a finalidade de gerenciar informações e ações, ainda existem inúmeras dificuldades no seu desenvolvimento e na sua aplicabilidade, no que tange aos pré-requisitos fundamentais ao avanço do SUS. Essa aplicabilidade permite um aumento na capacidade de resposta do Estado e da sociedade, em prol da saúde da população brasileira, visto que envolve outros atores, práticas, procedimentos e saberes, que caracterizam a transdisciplinaridade em saúde (SANTOS ET AL, 2014, p.834).

No processo informacional na área médica torna-se necessário o uso de um recurso que possibilite a transmissão de conteúdos com maior eficiência e eficácia, e também maior participação. A comunicação precisa de engajar a audiência, prover claro conhecimento da informação e promover a retenção dele (SMICIKLAS, 2012). Especialmente quando os conteúdos são implexos, como por exemplo relacionados a área da saúde que precisam ser divulgados com exatidão para públicos diversos. É imprescindível que a comunicação da informação seja assertiva e eficiente. E que muitas vezes fazem uso de infográficos em suas campanhas publicitárias (ESCOBAR E SPINILLO, 2016).

Nessa perspectiva, os infográficos se apresentaram como uma solução visual para a comunicação durante o crescimento urbano e o processo de industrialização, como afirma Moraes (2013), "A heterogeneidade do público ao qual mensagens e produtos se destinavam impôs a busca por formas de atingir as pessoas de modo a diminuir os efeitos que as diferenças entre elas pudessem provocar." (MORAES, p. 27, 2013). E se apresentam como uma ferramenta eficaz no design de informação, aplicado à área da saúde devido às suas características intrínsecas, unindo imagem e texto para representação de informações complexas de forma mais congruente e compreensível para um público diverso. O infográfico é considerado como uma junção entre informação e gráficos e pode ter textos de formas diferentes, tabelas, fluxos, diagramas, imagens e outras formas visuais. Quando os infográficos são usados como uma ferramenta comunicacional, é fisicamente mais fácil relatar e conectar a informação (SMICIKLAS, 2012).

\section{Metodologia}

Essa é uma pesquisa exploratória no campo das ciências sociais, especificamente no campo da gestão da informação e do design da informação. Na primeira fase foram selecionados e analisados, a partir do referencial teórico, cartazes de divulgação criados pelo SUS, Secretaria Estadual de Saúde de Minas Gerais e Secretarias Municipais de Saúde de quatro municípios mineiros, e infográficos publicados em por um jornal de circulação nacional e um regional. Para seleção dos cartazes foi feita 
uma busca através do Google, na aba de imagens com os termos "Campanha de divulgação vacinação contra gripe Minas Gerais 2017". Foram listados 500 resultados e selecionados somente sete que atendiam comprovadamente aos critérios de busca. Sendo assim, foram analisados os cartazes da campanha nacional criados pelo Ministério da Saúde, os criados pela Secretaria Estadual de Saúde e finalmente os criados pelas Secretarias Municipais de Saúde de Belo Horizonte, Rio Pomba, Campanha e Lagoa da Prata. Quanto aos infográficos, foi utilizado o mesmo método de busca através do Google, na aba imagens com os termos "Infográficos campanha vacinação contra gripe 2017”. Na segunda fase, essas peças foram analisadas através de um grupo focal formado por três professores universitários que lecionam em uma grande Instituição de Ensino Superior em Belo Horizonte. O roteiro de entrevista foi semi-estruturado e visava basicamente coletar informações sobre a percepção dos entrevistados sobre as sete peças analisadas nesse estudo. Essa pesquisa foi realizada em junho de 2017. Os resultados são descritos a seguir.

\section{Análise da divulgação da campanha de vacinação contra gripe 2017}

Para entender a razão da adesão abaixo do esperado por parte dos professores à campanha, foi realizada uma análise do conteúdo informacional sobre a perspectiva do design da informação. Primeiramente foi feito um estudo das similaridades e diferenças do conteúdo informacional dos cartazes de divulgação da campanha 2017 realizada na esfera federal, estadual e municipal em Minas Gerais.

A primeira peça analisada é a criada pelo SUS e de veiculação nacional. A campanha realizada pela União "Deixe a Gripe pra lá" apresentou fotos de pessoas representando os públicos-alvo, entre essas pessoas, o conhecido cantor e compositor Martinho da Vila, como representante do grupo de pessoas acima de 60 anos. Os demais sete grupos-alvo foram representados individualmente através de casting1 que caracterizaram por meio do uso de estereótipos cada um dos grupos. Nota-se que o objetivo primário da campanha é informar o período de vacinação e quem teria direito à imunização.

Tecnicamente a peça gráfica (Figura 1) foi corretamente diagramada com boa leiturabilidade e legibilidade, além da escolha harmônica das cores. Contudo, é importante ressaltar que a campanha de vacinação contra a gripe é destinada a um público diverso e heterogêneo, mesmo quando abordamos as categorias específicas. A escolha dos modelos certamente representou uma pequena parcela de cada grupo, o que não gerou a identificação com o restante. De acordo com ideia desenvolvida por Buckland (1991) pode-se afirmar que o cartaz deveria se tornar um "information-as-thing", um documento da informação agindo como um objeto instrucional.

\footnotetext{
${ }^{1}$ Em publicidade, um dos conceitos do termo casting, consiste em selecionar profissionais para atuar como modelo em campanha publicitária.
} 


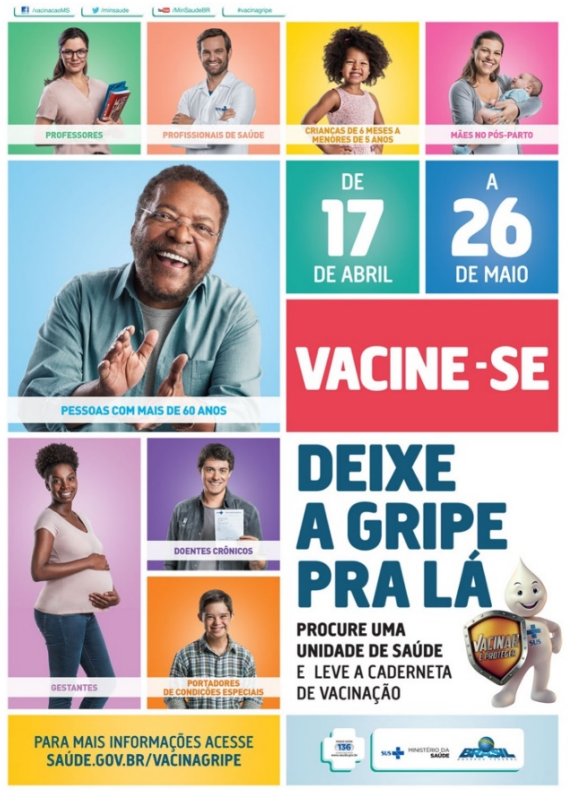

Figura 1. Cartaz de divulgação da campanha SUS 2017

A campanha realizada pela Secretaria Estadual de Saúde do Estado de Minas Gerais, nomeada "Proteja-se", trouxe todos os grupos de forma unificada em uma uma única foto (Figura 2). Por ser uma campanha em nível estadual, faltou incluir elementos regionais no repertório midiático, a "mineiridade" como base para a construção da comunicação. Tecnicamente a peça gráfica também foi corretamente diagramada com boa leiturabilidade e legibilidade. O layout é neutro com um fundo em degradê azul e o casting segue o estereótipo da campanha da União com o mesmo objetivo primário informar o período e quais são os públicos-alvo do processo de vacinação. Entretanto, há a presença de ilustrações sobre atitudes do dia-a-dia que são úteis na prevenção da gripe, o que pode ocasionar conflito de interesses de informação, já que a vacinação imuniza contra a gripe.

No cartaz foi inserido um QR Code ao lado do endereço do site, www.saude.mg.gov.br/gripe que encaminha o usuário ao mesmo endereço eletrônico, onde é possível acessar diversas informações sobre a campanha; sobre a gripe, os vírus, riscos, prevenção, entre outros. Quando acessado, o cartaz pode transformar-se em "information-as-thing", devido a quantidade e qualidade das informações contidas no site.
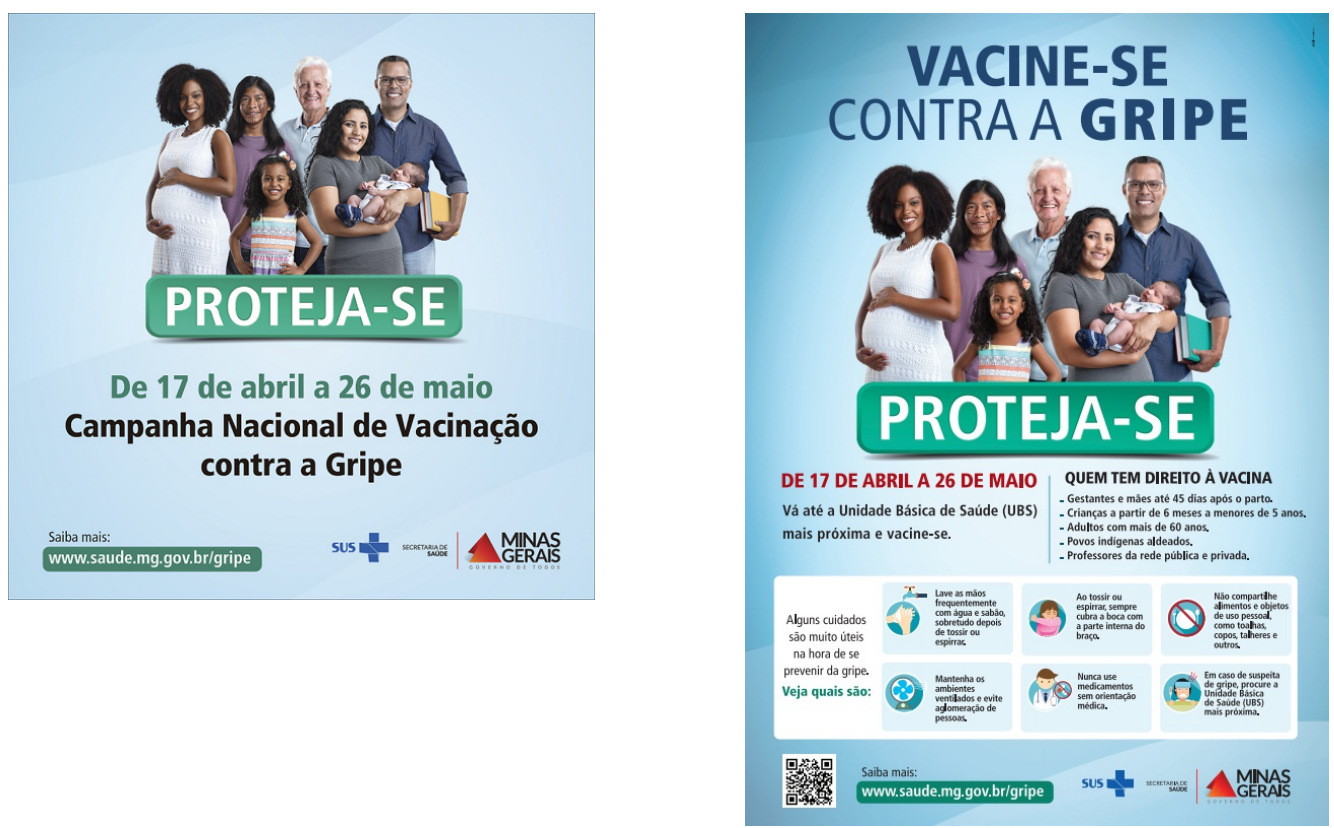

Figura 2. Cartaz de divulgação da campanha SES MG 2017 
As campanhas municipais apresentadas abaixo, da mesma forma que as anteriores não apresentam problemas de leiturabilidade ou legibilidade e foram corretamente diagramadas.

A Prefeitura de Belo Horizonte desenvolveu uma campanha intitulada "Vacinação contra gripe" (Figura 3), ao contrário das campanhas apresentadas até aqui, não possui fotos de modelos que representem os grupos-alvo para o desenvolvimento das peças gráficas. Essas, foram substituídas pela ilustração de uma seringa. Considerando que o público-alvo é diverso e que não foram utilizadas imagens ilustrativas para representar a campanha contra a gripe, as pessoas que não são alfabetizadas veriam apenas uma grande seringa. Já as pessoas alfabetizadas fariam a leitura do conteúdo, contudo, a imagem da seringa sobressai como elemento visual e sua representatividade personifica a experiência negativa existente no processo de imunização, que é ser espetado por uma agulha.

A prefeitura de Rio Pomba (figura 4), utilizou a foto de uma única criança, que está sorrindo enquanto é vacinada, o que provoca estranheza devido ao conteúdo paradoxal. A prefeitura de Campanha (Figura 5) apresentou uma campanha utilizando pictogramas, que em tese são mais genéricos na representação dos grupos por sua síntese visual. Outro ícone utilizado foi a ilustração do Zé Gotinha, consagrado mascote das campanhas de imunização contra a Poliomelite, que posteriormente foi utilizado nas outras ações de vacinação. A prefeitura de Lagoa da Prata (Figura 6) assim como Belo Horizonte e Rio Pomba utilizou um repertório midiático da experiência negativa do processo de imunização, o foco é a consagrada "agulhada" e o "beliscão".

Tecnicamente, as campanhas municipais não apresentaram nenhuma falha grave, todavia, no que tange os níveis de regionalidade seria esperado que a comunicação fosse mais específica e próxima do público de cada cidade, utilizando jargões e termos intrínsecos de cada cidade. O que poderia contribuir para transformar as informações em processo, de acordo com o conceito de "informationas-process" de Buckland (1991).

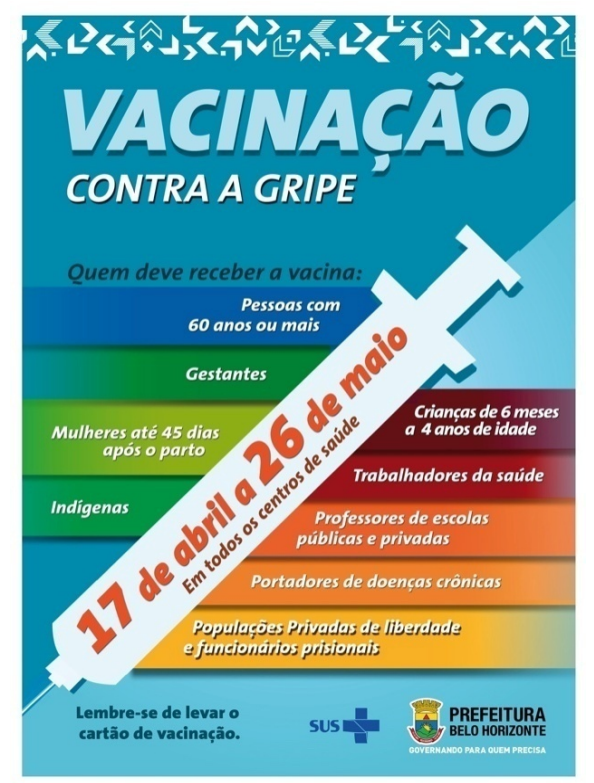

Figura 3. Cartaz de divulgação da campanha PBH MG 2017 


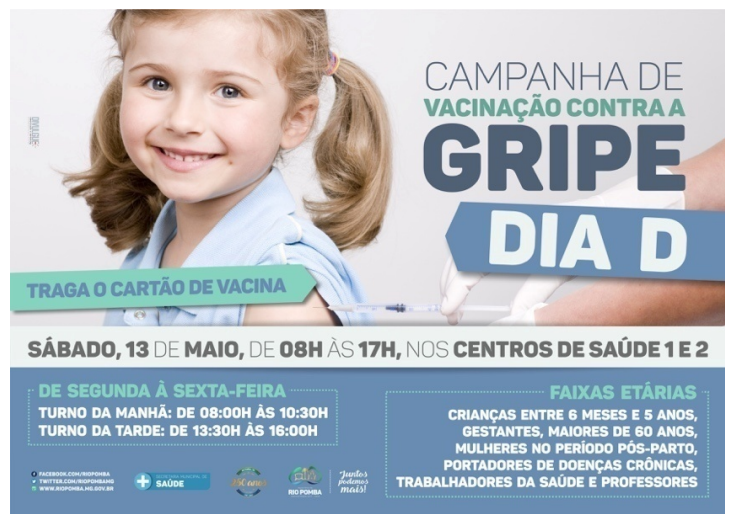

Figura 4. Cartaz de divulgação da campanha vacinação Município Rio Pomba 2017
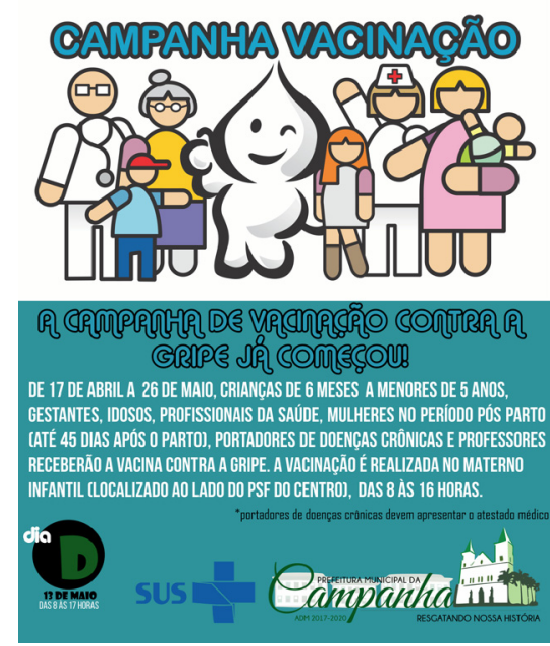

Figura 5. Cartaz de divulgação da campanha vacinação Município de Campanha/MG 2017

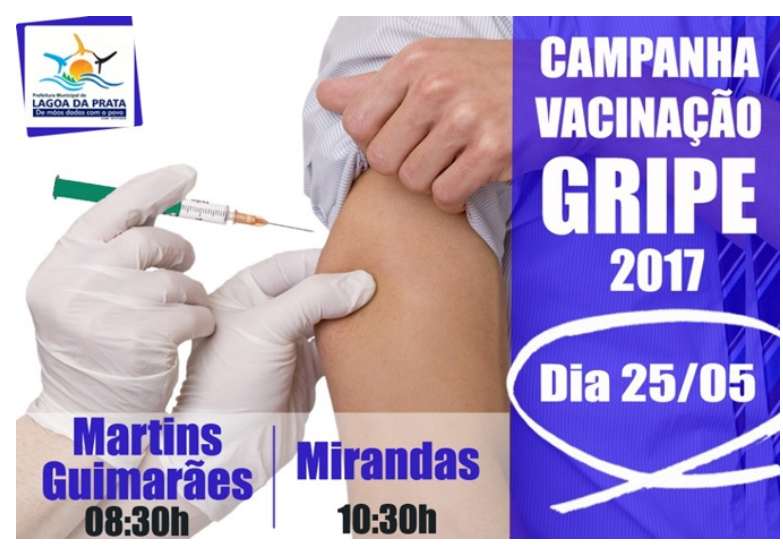

Figura 6: Cartaz de divulgação da campanha vacinação Município Lagoa da Prata/MG 2017

Para realizar a análise do conteúdo informacional dos infográficos da campanha contra gripe 2017, optou-se por realizar uma busca através do Google na aba geral com os termos "Infográficos campanha vacinação 2017". Foram listados 283.000 resultados. Foram abertos todos os links das cinco primeiras páginas e lidos os conteúdos das reportagens em busca dos infográficos. Entre elas, somente duas atendiam comprovadamente aos critérios de busca. Sendo assim, foram analisados os infográficos do site do Jornal Hoje em Dia (Figura 7) e do Jornal Folha de São Paulo (Figura 8). 


\section{Balanco}

DISTRIBUIÇÇO DA IMUNIZAÇATO EM BH E MC

BELO HORIZONTE (EM MLLARES)

\begin{tabular}{|c|c|c|c|}
\hline DIDOS & TORKA NECIMAR & 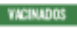 & MDTMLALADES \\
\hline Criancas de 6 meses a 4 anos & 127,4 & 54,5 & 72,9 \\
\hline Trabalhadores da saude & 95 & 72,7 & 22,3 \\
\hline Protessores & 56 & 20,4 & 35,6 \\
\hline Idosos & 302 & 213 & 89 \\
\hline Cestantes & 24 & 11,4 & 12,6 \\
\hline Puerperas & 3,9 & 3,1 & 0,8 \\
\hline Populaçăo privada de liberdade & 2,4 & 1,8 & 0,6 \\
\hline Agentes penitenciários & 2,4 & 1,8 & 0,6 \\
\hline Portador doença crónica & 214 & 128 & 86 \\
\hline Total & 827,1 & 506,7 & 320,4 \\
\hline
\end{tabular}

MINAS GERAIS (EM MILHARES)

\begin{tabular}{|c|c|c|c|}
\hline Chlos & TORN AVISINAR & Welineors & 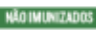 \\
\hline Criancas de 6 meses a 4 anos & $1.174,7$ & 594 & 580,6 \\
\hline Trabalhadores da saúde & 424 & 296 & 128,3 \\
\hline Protessores & 253,6 & 152,2 & 10,4 \\
\hline Idosos & $2.337,6$ & 1.684 & 653,5 \\
\hline Gestantes & 200,4 & 106,6 & 94 \\
\hline Puêrperas & 33 & 25 & 7,9 \\
\hline Indigenas & 12 & 5,8 & 6,1 \\
\hline Iotal & $4.435,8$ & 2.886 & 1.550 \\
\hline
\end{tabular}

$\longrightarrow$ Øી\% DO PÚBLICO-ALVO VACINADO EM MINAS GERAIS

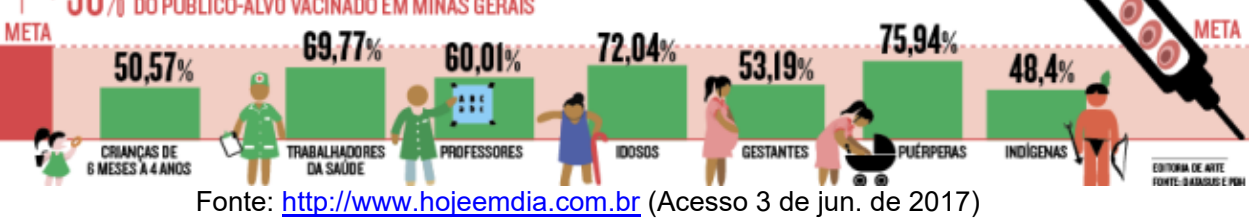

Fonte: http://www.hojeemdia.com.br (Acesso 3 de jun. de 2017)

Figura 7. Infográfico sobre Campanha Vacinação contra gripe 2017 Jornal Hoje em Dia

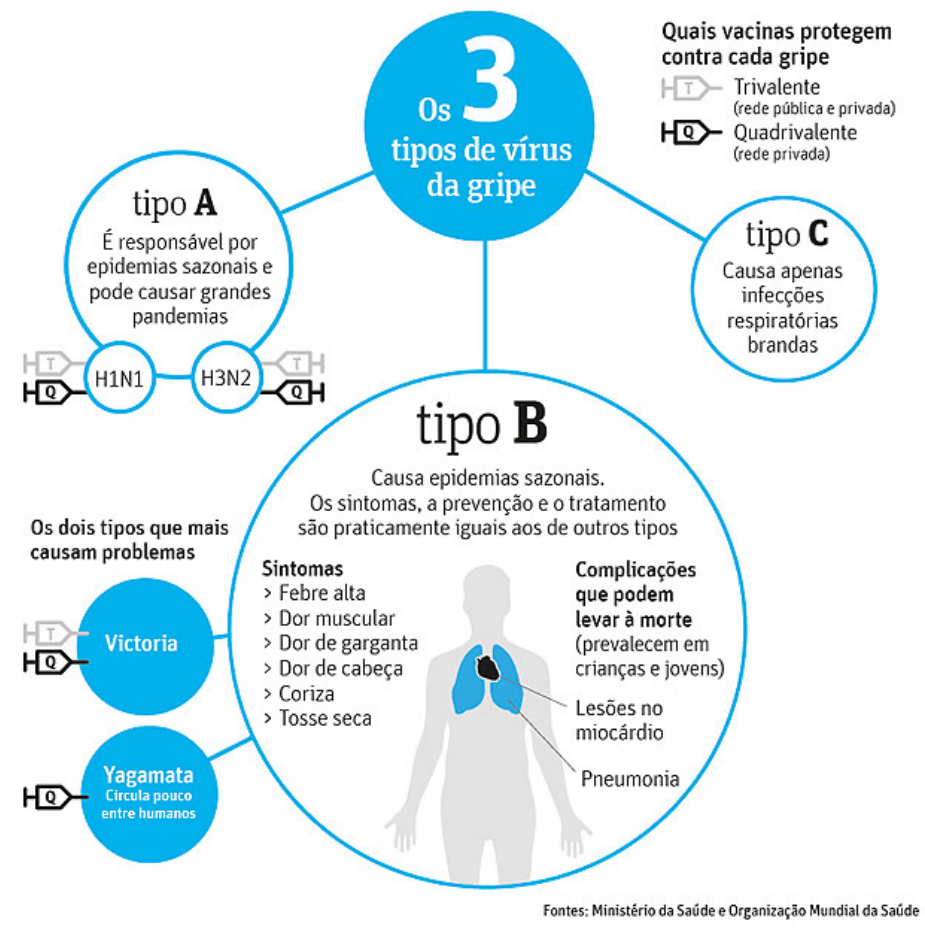

Fonte: http://www.folha.uol.com.br (Acesso 3 de jun. de 2017)

Figura 8. Infográfico sobre Campanha Vacinação contra gripe 2017 Jornal Folha de São Paulo

Os dois infográficos não são meros elementos decorativos ou de entretenimento nas reportagens. Eles podem ser considerados dentro da perspectiva de Buckland (1991) como informativos, já que comunicam de forma simples e ágil conhecimentos complexos úteis para os leitores a respeito das formas de contrair a doença, suas variações, sintomas e vacinas que podem preveni-las, como no caso do infográfico da Folha de São Paulo, ou resultados numéricos e percentuais da campanha em comparação com a meta, como no caso do Jornal Hoje em Dia.

As representações icônicas e simbólicas de uma forma geral apresentadas nas mídias das campanhas analisadas, foi baseada em dois argumentos: a representação dos públicos-alvo ou as experiências negativas como o ato técnico da vacinação que foi representado pelo ícone da seringa ilustrada ou imagem fotográfica. A experiência da vacinação geralmente não é agradável, principalmente para as 
crianças, que tem momentos de muita tensão antes e durante o processo, não sendo dessa forma um bom argumento para convencer a população a ir tomar a dose da vacina.

Uma possibilidade mais eficaz, demonstrada em alguns exemplos de infográficos divulgados em mídias jornalísticas, foi o tratamento da informação sobre os benefícios e a importância para a saúde pública de vacinar as pessoas que pertencem ao grupo de risco. Como os profissionais da saúde e idosos, além do novo grupo, os professores. Quiçá o das informações fossem dessa natureza e apresentados em ilustrações e infográficos, acredita-se que mais pessoas poderiam aderir à campanha por ter maior esclarecimento sobre a importância da vacinação.

Partindo da premissa que professores têm um nível diferente de absorção e entendimento de informação pela natureza da sua profissão, foi feita uma pesquisa qualitativa através de um grupo de foco com professores, cujo objetivo foi o de aprofundar as análises realizadas nessa pesquisa. Abaixo segue a síntese dos principais pontos coletados.

Dos entrevistados, um é especialista, um é mestre e uma é doutoranda. Os três não foram vacinados em 2017. Um professor não recordou a data da vacinação, a outra não se sentiu motivada a procurar o posto de saúde por não ter certeza sobre a eficácia da vacina e o outro relatou que procuraria o posto para ser vacinado nos próximos dias e não estava ciente que a campanha já havia se encerrado. Um ponto em comum que merece ser destacado é que os participantes alegaram não ter tido qualquer contato com as peças de divulgação criadas pelo SUS e secretarias estadual e municipal de saúde. Um deles teve conhecimento da campanha por uma reportagem exibida na televisão e outra na internet. Um deles obteve a informação sobre a campanha por meio de uma conversa informal com outro professor e a professora por mensagem através de um aplicativo de comunicação para telefone móvel. Nenhum dos três professores leu e visualizou as reportagens com os infográficos selecionadas para esse estudo.

Foram mostrados os cartazes de divulgação da campanha através da tela do computador para os três entrevistados para que eles pudessem analisar e opinar sobre o conteúdo informacional de cada uma das peças e posteriormente foi feito o mesmo com os infográficos dos jornais supracitados. Um dos entrevistados ponderou que o cartaz criado pela Secretaria de Saúde da Prefeitura de Belo Horizonte, onde se vê a ilustração de uma seringa, criava o sentimento de repulsa à vacinação. Para ele a seringa remetia a algo doloroso, ele acrescentou que "ninguém se sente bem em tomar uma agulhada". Para um dos entrevistados, o cartaz criado pela Ministério da Saúde, apesar de esteticamente atraente, "comunicava pouco". Perguntado sobre o que isso significava, ele explicou que tinha pouca informação para convencê-lo e que a reprentação do professor no cartaz não gerou nele identificação. O cartaz criado pela Secretaria Estadual de Saúde foi tratado com indiferença, pois não despertou qualquer comentário positivo ou negativo entre os entrevistados. As peças que mais despertaram o interesse dos participantes foram os infográficos, que segundo eles, apresentavam a informação de uma forma mais organizada e confiável. Segundo os professores, se tivessem visto os infográficos provavelmente se sentiriam mais motivados a comparecer aos postos de vacinação, do que através do que foi exibido nos cartazes.

\section{Discussão}

Se o design da informação tivesse sido utilizado na elaboração da campanha de divulgação, melhores resultados de engajamento e assimilação dos conceitos informacionais-chave por parte dos públicosalvo, especialmente os professores, teriam sido obtidos?

A campanha de divulgação aconteceu de forma independente e sem unidade entre os diversos atores da campanha de vacinação, dando a entender que não havia uma coordenação em termos informacionais.

Os estudos iniciais realizados e aqui apresentados apontam a necessidade estudos etnográficos mais profundos para subsidiar a criação das próximas campanhas. Há que se considerar futuramente a questão da regionalização versus generalização. Ao mesmo tempo que foi possível perceber que a liberdade para a criação de peças gráficas próprias nos níveis estaduais e municipais, poderiam propiciar uma comunicação mais eficiente, levanta-se o questionamento sobre a unidade da campanha. Outro ponto a ser trabalhado é a existência de mão de obra especializada para realiza-las com a qualidade necessária regionalmente. Frascara (2004) pondera sobre o papel holístico do designer no processo de gestão da informação e coordenação de profissionais de diferentes áreas que trabalharão juntos para a construção das campanhas publicitárias. Em virtude dessa reflexão, surgem hipotéses para serem averiguadas na continuação da pesquisa. Os municípios e estados possuem profissionais capazes de criar referências visuais e de linguagem, adequadas para a criação de campanhas regionais 
com repertório midiático condizente com o público? Espera-se com o desenvolvimento dessa pesquisa levantar informações que possam ser utilizadas nas campanhas para a área de saúde, com toda a sua diversidade e especificidade.

An approach on information design on the flu vaccination ad campaign in 2017 among the target: teachers of the public and private sectors in Minas Gerais

abstract:

The objective of this study is to analyze the reasons for low adherence by teachers, the vaccination campaign against the influenza 2017, which began on April 17 with the title: "National Vaccination Campaign against Flu 2017", through an analysis of the information content of printed graphic pieces (posters, leaflets and flyers) created and used by public agencies and newspaper companies in the dissemination. This study was based on an exploratory research composed of two phases. In the first phase, the publicity posters created by the SUS, the Minas Gerais State Health Secretariat and the Municipal Health Secretariats of four Minas Gerais municipalities were selected: Belo Horizonte Health Secretariats, Pomba River, Campaign and Lagoa da Prata; infographics published in the Folha de São Paulo newspaper of national circulation and in the newspaper Hoje em Dia of regional circulation, based on the theoretical assumptions of information design. In the second phase, the same pieces were analyzed regarding content and informational efficiency by teachers of a higher education institution in a focus group. From these two analyzes it was possible to raise technical flaws in the content and to verify that there is a need to conduct an ethnographic research to increase communicational efficiency with this target audience in the next influenza vaccination campaigns. Based on the results obtained, it reinforces the need for the participation of an information design professional in the process of designing and adapting the graphic pieces in campaigns of the genre.

Key Words:

Information Design; Information in the vaccination campaign; Teacher awareness.

\section{Referências bibliográficas}

BARRETO, A. O que é informação e o que é Ciência da Informação. Jornal da Ciência. Notícias de Ciência e Tecnologia, SBPC, n. 1802, jun. 2001.

BRANSFORD, John D.; BROWN, Ann L.; COCKING, Rodney R. How People Learn: Brain, Mind, Experience, andSchool. Washington, D.C: NationalAcademy Press. 2000.

BUCKLAND, M. Information as thing. Journalof American Society of Information Science.v.42, n.5, 1991.

CORDEIRO, William Robson. Infografia interativa na redação: o exemplo do Diário do Nordeste. Mossoró: Sarau das Letras, 2013.

COUTINHO, Clara; LISBÔA, Eliana. Sociedade da informação, do conhecimento e da aprendizagem: desafios para educação no século XXI. In Revista de Educação, Vol. XVIII, n. 1, 2011 | $5-22$.

DICK, Maurício Elias; GONÇALVES, Berenice Santos; VITORINO, Elizete Vieira. Design da informação e competência em informação: relações possíveis. In Revista Infodesign, São Paulo, V.17 - n. 1, 2017, p. 2-13. 
ESCOBAR, Bolívar Teston de; SPINILLO, Carla Galvão. Retórica visual na infografia sobre saúde. In Revista Infodesign. São Paulo, V. 16 - n. 2, 2016, p. 162 - 179. Disponível em https://www.infodesign.org.br/infodesign/article/viewFile/471/282 Acesso em 09 jun. 2017

FOLHA DE SÃO PAULO. A campanha de vacinação contra a gripe começa nesta segunda feira. Disponível em http://www1.folha.uol.com.br/cotidiano/2017/04/1875997-campanha-devacinacao-contra-a-gripe-comeca-nesta-segunda-feira.shtml. Acesso em 30 mai. 2017

FOLHA DE SÃO PAULO. Baixa adesão força governo a prorrogar vacinação contra a gripe. Disponível em http://www1.folha.uol.com.br/cotidiano/2017/05/1887605-baixa-adesao-forca-governoa-prorrogar-vacinacao-contra-a-gripe.shtml. Acesso em 28 mai. 2017.

FRASCARA, Jorge. Communication design: principles, methods, and practice. Nova York: Allworth Press, 2004.

FREITAS, Ranielder Fábio de; WAECHTER, Hans da Nóbrega; COUTINHO, Solange Galvão; GUBERT, Fabiane do Amaral. Design da Informação, Comunicação, Saúde e prevenção das DST/Aids: estudo sistemático. C\&S: São Bernardo do Campo, v. 35, n. 2, p. 291-314, jan./jun. 2014 DOI: http://dx.doi.org/10.15603/2175-7755/cs.v35n2p291-314, acesso em 02 mai. 2017.

FUNDAÇÃO NACIONAL DE SAÚDE. Guia de Vigilância Epidemiológica. 4 ed. Brasília.1998. Disponível em

http://cmdss2011.org/site/wp-content/uploads/2011/07/Declara\%C3\%A7\%C3\%A3o-Alma-Ata.pdf

MARREIROS, A. C.; TEIXEIRA, A.M.S. SILVA, D. A. COSTA, K. C. BRICKS, L. F. CHAVES, M. P. SILVA, R. C. M. S. S. REBELO R. C. F. CARVALHO, S. D.; PEREIRA. S. F. ; ALMEIDA, W. A. F. A. Informe Técnico Vacinação Influenza 2016. Brasília: CGPNI Ministério da Saúde. 2016.

MORAES, Ary. Infografia: história e projeto. São Paulo: Blucher, 2013.

NEWS MEDICAL. 0 que é uma pandemia. Disponível em http://www.newsmedical.net/health/What-is-a-Pandemic-(Portuguese).aspx. Acesso em 30 mai. 2017.

O GLOBO. Campanha nacional de vacinação contra a gripe é prorrogada. Disponível em http://g1.globo.com/bemestar/noticia/campanha-nacional-de-vacinacao-contra-a-gripe-eprorrogada.ghtml

O GLOBO. Dia D da Campanha de Vacinação contra a a gripe influenza será neste sábado. Disponível em http://gazetaweb.globo.com/portal/noticia/2017/05/dia-d-de-campanha-de-vacinacaocontra-a-gripe-influenza-sera-neste-sabado-_33164.php. Acesso em 11 jun. 2017.

PORTAL BRASIL. As principais ações do programa nacional de imunizações. Disponível em http://www.brasil.gov.br/saude/2014/04/confira-as-principais-acoes-do-programa-nacional-deimunizacoes-1. Acesso em 28 mai. 2017.

PORTAL BRASIL. Campanhas PNI. Disponível em http://portalarquivos.saude.gov.br/campanhas/pni/o-que-e.html. Acesso em 28 mai. 2017.

PORTAL BRASIL. Grupos prioritários ainda não atingiram meta de vacinação contra a gripe. Disponível em http://www.brasil.gov.br/saude/2017/05/grupos-prioritarios-ainda-nao-atingiram-meta-devacinacao-contra-a-gripe. Acesso em 30 mai. 2017.

PORTAL BRASIL. Anvisa define nova composição da vacina contra gripe para 2017. Disponível em http://www.brasil.gov.br/saude/2016/10/anvisa-define-nova-composicao-da-vacinacontra-gripe-para-2017. Acesso em 30 mai. 2017.

PORTAL SAÚDE. Campanha contra a gripe vai vacinar 54,2 milhões em todo o país. Disponível em http://portalsaude.saude.gov.br/index.php/cidadao/principal/agencia-saude/28068campanha-contra-a-gripe-vai-vacinar-54-2-milhoes-em-todo-o-pais. Acesso em 30 mai. 2017.

PORTAL SAÚDE. Influenza. Disponível em http://portalsaude.saude.gov.br/index.php/oministerio/principal/secretarias/svs/influenza. Acesso em 30 mai. 2017.

SANTOS, Sérgio Ribeiro dos; FEREIRA, Jocelly de Araújo; SANTA CRUZ, EgillaneMadza Mendes; LEITE, Elanne Meire de Almeida Mendes; PESSOA, Juliana da Costa Santos; Sistema de Informação em Saúde: Gestão e Assistência no Sistema Único de Saúde. CogitareEnferm. 
2014 Out/Dez; 19(4):833-40. Disponível em http://www.saude.ufpr.br/portal/revistacogitare/wpcontent/uploads/sites/28/2016/10/35347-145144-1-PB.pdf, acesso em 29 mai. 2017

SECRETARIA DE ESTADO DA SAÚDE MINAS GERAIS. Começou a 19a campanha nacionaldevacinação contra a gripe2017. Disponível em http://blog.saude.mg.gov.br/2017/04/17/vacinagripe-comecou-a19a-campanha-nacional-de-vacinacao-contra-a-gripe-2017/

SMICIKLAS, Mark. The Power of Infographics: Using Pictures to Communicate and Connect with YourAudience. Indiana: QUE Publishing, 2012.

SUS. Calendário Nacional de Vacinação da Criança 2016. Disponível em http://saude.es.gov.br/Media/sesa/Imunização/Calendário\%20Nacional\%20de\%20Vacinação\%20da\% 20Criança\%20-\%20PNI\%20-\%202016.pdf. Acesso em 28 mai. 2017.

SUS. Informe Técnico19 ${ }^{a}$ Campanha Nacional de Vacinação contra a Influenza. Brasília 2017. Disponível

http://pni.datasus.gov.br/sipni/03\%2003\%202017\%20Informe_Cp_Influenza\%20_\%20final.pdf. Acesso em 14 jun. 2017.

TIMPERLEY, H., WILSON, A., BARRAR, H. \& FUNG, I. Teacher Professional Learning and Development: Best Evidence Synthesis Iteration. Wellington: Ministry of Education, 2008. 